\title{
Prediction of Treatment Response to Neoadjuvant Chemotherapy in Breast Cancer by Subtype Using Tumor-infiltrating Lymphocytes
}

\author{
YUKA ASANO $^{1}$, SHINICHIRO KASHIWAGI ${ }^{1}$, WATARU GOTO ${ }^{1}$, KOJI TAKADA ${ }^{1}$, \\ KATSUYUKI TAKAHASHI ${ }^{2}$, TAKAHARU HATANO ${ }^{3}$, TSUTOMU TAKASHIMA ${ }^{1}$, SHUHEI TOMITA ${ }^{2}$, \\ HISASHI MOTOMURA ${ }^{3}$, MASAHIKO OHSAWA ${ }^{4}$, KOSEI HIRAKAWA ${ }^{1}$ and MASAICHI OHIRA ${ }^{1}$ \\ Departments of ${ }^{1}$ Surgical Oncology, ${ }^{2}$ Pharmacology, ${ }^{3}$ Plastic and Reconstructive Surgery, and \\ ${ }^{4}$ Diagnostic Pathology, Osaka City University Graduate School of Medicine, Osaka, Japan
}

\begin{abstract}
Background/Aim: Recent interest has focused on the significance of tumor-infiltrating lymphocytes (TILs) on the efficacies and outcomes of the treatment in breast cancer $(B C)$. Based on the recent international recommendation to standardize the evaluation method, the clinical validity and utility of TILs in patients who underwent neoadjuvant chemotherapy (NAC) were investigated in the present study. Patients and Methods: TILs were evaluated in 177 patients with BC treated with NAC and subsequent curative surgery. The correlation between TILs evaluated according to the standard method and prognosis, including the efficacy of NAC, was investigated retrospectively. Results: In the high-TIL group ( $n=96)$ compared to the low-TIL group $(n=81)$, triple-negative breast cancer $(T N B C)(p<0.001)$ and human epidermal growth factor receptor 2-enriched breast cancer (HER2BC) $(p=0.040)$ were significantly more frequent, and the pathological complete response $(p C R)$ rate was significantly higher $(p=0.003)$. Among patients with TNBC and those with HER2BC, the $p C R$ rate was significantly higher in the high-TIL group than in the low-TIL group ( $p=0.013$ and $p=0.014$, respectively). Multivariable analysis also showed that high-TIL status was an independent factor predicting favorable prognosis (hazard $\operatorname{ratio}(H R)=0.24, p=0.023$ and $H R=0.13, p=0.036)$. Biopsy specimens from local recurrence after successful NAC
\end{abstract}

This article is freely accessible online.

Correspondence to: Shinichiro Kashiwagi, MD, Ph.D., Osaka City University Graduate School of Medicine, 1-4-3 Asahi-machi, Abeno-ku, Osaka 545-8585, Japan. Tel: +81 666453838, Fax: +81 666466450, e-mail: spqv9ke9@view.ocn.ne.jp

Key Words: Tumor-infiltrating lymphocytes, triple-negative breast cancer, pathological complete response, neoadjuvant chemotherapy, HER2-enriched. frequently showed TILs decreased. Conclusion: TILs may be a biomarker for predicting treatment response to NAC in patients with TNBC and HER2BC. A decrease in TILs may also be associated with tumor recurrence.

Monitoring the immunological response to cancer in the microenvironment of the interaction between tumor and the body plays an important role in predicting treatment response and outcomes $(1,2)$. Recent interest has focused on the morphological evaluation of tumor-infiltrating lymphocytes (TILs) in breast cancer (BC) and on the evidence showing their clinical relevance (3-6). Loi and Denkert et al. showed that the combination analysis of TILs and immune-related gene mRNA of cancer cells was useful in predicting the response to carboplatin-based neoadjuvant chemotherapy (NAC) in BC (4). Two phase III Eastern Cooperative Oncology Group (ECOG) trials have also shown a positive correlation between TILs and favorable outcomes of the treatements (3). This usefulness has been shown to be enhanced in triple-negative breast cancer (TNBC) and human epidermal growth factor receptor 2 (HER2)-positive BC (5-7), and differences in immunological responses based on subtype have been suggested.

The concept of immune editing has recently been proposed (8). BC has not conventionally been regarded as a cancer that develops due to abnormal immune function (9). However, programmed cell death-1 (PD-1) and programmed death-ligand-1 (PDL-1) expression are reported to be correlated with outcomes in BC (10-12), and this is expected to play an important role in tailor-made management in $\mathrm{BC}$ by further systemic therapy.

No consensus has yet been reached on standard methods for pathological evaluation of TILs. Therefore, methods of evaluation have differed in reports showing the clinical relevance of TILs (13-15). An International Working Group (2014) announced recommendations for evaluating TILs in an effort to improve consistency and reproducibility (16). We 
believe that the number of TILs may become a predictive marker in NAC of TNBC and human epidermal growth factor receptor 2-enriched breast cancer (HER2BC) in which immunoreactivity is high. Furthermore, we hypothesized that a change of TILs before and after NAC contributes to recurrence. In this study, the clinical validity and utility of TILs in NAC were investigated based on this recommendation with a stratified analysis by BC subtype. Changes in TILs after recurrence, which have seldom been reported to date (17), are also discussed.

\section{Materials and Methods}

Patient background. A total of 177 patients with resectable, early-stage BC diagnosed as stage IIA (T1, N1, M0 or T2, N0, M0), IIB (T2, N1, $\mathrm{M} 0$ or T3, N0, M0), or IIIA (T1-2, N2, M0 or T3, N1-2, M0) were treated with NAC between 2007 and 2013. Tumor stage and T and N factors were stratified based on the Seventh Edition of the TNM Classification of Malignant Tumors (18). Breast cancer was confirmed histologically by core needle biopsy (CNB) and staged by systemic imaging studies using computed tomography (CT), ultrasonography (US), and bone scintigraphy. BC was classified into subtypes according to the immunohistochemical expression of estrogen receptor (ER), progesterone receptor (PR), HER2, and Ki67. The cutoffs for ER positivity and PR positivity were both $>0 \%$ positively stained tumor cells with nuclear staining. Hormone receptor-positive breast cancer (HRBC) was defined as ER-positive with/without PgR positivity. Tumors with $3+$ HER2 on immunohistochemical staining were considered to show HER2 overexpression; tumors with 2+ HER2 were further analyzed by fluorescence in situ hybridization; and those with HER2/CEP17 $\geq 2.0$ were also considered to exhibit HER2 overexpression (19). Ki67-labeling index with $\geq 14 \%$ of tumor cells with nuclear staining was considered positive.

All patients received a standardized protocol of NAC consisting of four courses of FEC100 $\left(500 \mathrm{mg} / \mathrm{m}^{2}\right.$ fluorouracil, $100 \mathrm{mg} / \mathrm{m}^{2}$ epirubicin, and $500 \mathrm{mg} / \mathrm{m}^{2}$ cyclophosphamide) every 3 weeks, followed by 12 courses of $80 \mathrm{mg} / \mathrm{m}^{2}$ paclitaxel administered weekly $(20,21)$. Patients with HER2-positive BC were additionally administered trastuzumab weekly $(2 \mathrm{mg} / \mathrm{kg})$ or tri-weekly $(6 \mathrm{mg} / \mathrm{kg})$ during paclitaxel treatment (22). All patients underwent chemotherapy as outpatients. Therapeutic antitumor effects were assessed according to the Response Evaluation Criteria in Solid Tumors (RECIST) (23). Patients underwent mastectomy or breastconserving surgery after NAC. All patients who underwent breastconserving surgery were administered postoperative radiotherapy to the remnant breast. Overall survival (OS) time was the period from the initiation of NAC to the time of death from any cause. Diseasefree survival (DFS) was defined as freedom from all local, locoregional, and distant recurrence. All patients were followed up by physical examination every 3 months, US every 6 months, and $\mathrm{CT}$ and bone scintigraphy annually. The median follow-up period was 3.4 years (range $=0.6-6$ years) for the assessment of OS and 3.1 years (range $=0.1-6$ years) for DFS. The study protocol was approved by the Ethics Committee of Osaka City University (\#926). Written, informed consent was obtained from all participants.

Histopathological evaluation. The pathological effect of chemotherapy was assessed for resected primary tumors after NAC. Pathological complete response (pCR) was defined as the complete disappearance of the invasive components of the lesion with or without intraductal components, including the lymph nodes according to the National Surgical Adjuvant Breast and Bowel Project (NSABP) B-18 protocol (24). Histopathological assessment of predictive factors was made for $\mathrm{CNB}$ specimens at the time of $\mathrm{BC}$ diagnosis. Histopathological parameters examined included nuclear grade, histological type, presence of TILs, apoptosis, and correlation of these parameters with intrinsic subtypes and pCR.

Histopathological analysis of the percentage of TILs was evaluated on a single full-face hematoxylin and eosin-stained tumor section using criteria described by Salgado et al. (16). TILs were defined as the infiltrating lymphocytes within tumor stroma and expressed as a proportion of the field investigated $(15,16,25,26)$, and the number of TILs in stroma surrounding the stained cancer cells was quantitatively measured in each field under $\times 400$ magnification. Areas of in situ carcinoma and crush artifacts were not included. Proportional scores were defined as 3, 2, 1, and 0 if the area of stroma with lymphoplasmacytic infiltration around invasive tumor cell nests was $>50 \%,>10-50 \%, \leq 10 \%$, and absent, respectively (Figure 1). A score of $\geq 2$ was considered positive for TILs, whereas scores of 1 and 0 were considered negative. Histopathological evaluation of TILs was jointly performed by two breast pathologists who were blinded to clinical information, including treatment allocation and outcomes.

Statistical analysis. Statistical analysis was performed using SPSS version 19.0 statistical software package (IBM, Armonk, NY, USA). The associations between TILs and clinicopathological variables were examined using chi-squared tests. Multivariable analysis of pCR was carried out using a binary logistic regression model. The Kaplan-Meier method was used to estimate DFS, and OS, and the results were compared between groups with log-rank tests. The Cox proportional hazards model was used to compute univariable and multivariable hazard ratios (HR) for the study parameters with $95 \%$ confidence interval (CI), and used in a backward stepwise method for variable selection in multivariate analyses. $p$-Values of less than 0.05 were considered significant. Cutoff values for different biomarkers included in this study were chosen before statistical analysis.

\section{Results}

Clinicopathological responses of primary $B C$ to $N A C$. The $\mathrm{BC}$ subtypes among the 177 patients who received NAC were TNBC in $61(34.5 \%)$, HER2BC in $36(20.3 \%)$, and HRBC in $80(45.2 \%)$ patients. Treatment response was pCR in 67 $(37.9 \%)$ and non-pCR in $110(62.1 \%)$ patients. Based on subtype, pCR was achieved in $28(45.9 \%)$ patients with TNBC, $18(50.0 \%)$ with HER2BC, and $21(26.3 \%)$ with HRBC.

TILs in all BC. TILs were determined in every sample and ranged from 0 to $96 \%$ (mean $=14$; median $=16$; standard deviation=5). The proportions of TILs were categorized into high and low groups using a cut-off value of $10 \%$. There were $96(54.2 \%)$ patients in the high-TIL group and $81(45.8 \%)$ patients in the low-TIL group. Patients were divided into high-TIL and low-TIL groups, and the clinicopathological characteristics of each group were examined. 

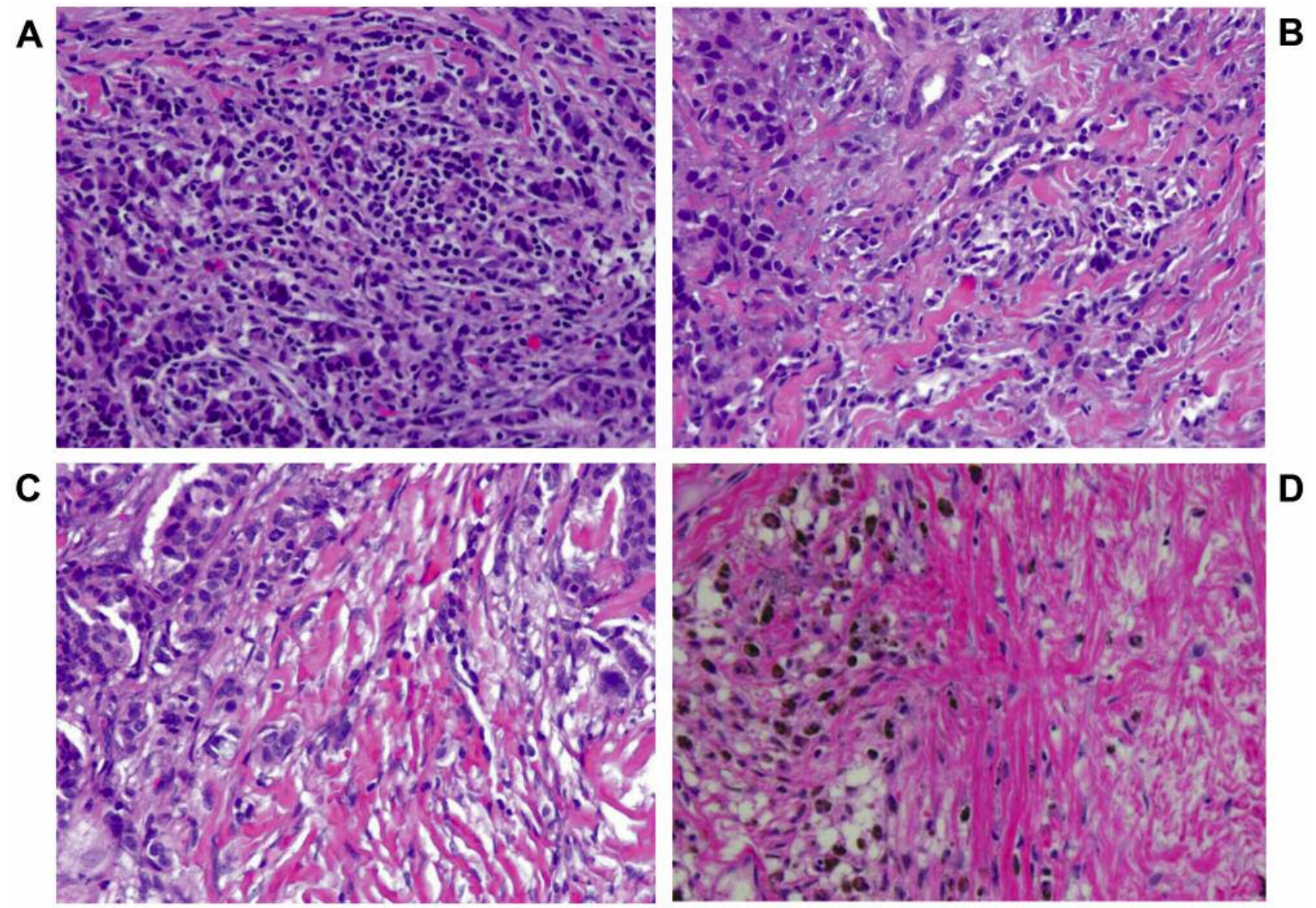

Figure 1. Histopathological evaluation. Histopathological analysis of the percentage of tumor-infiltrating lymphocytes (TILs) was performed on a single full-face hematoxylin and eosin-stained tumor section. TILs were defined as the percentage of tumor stroma containing infiltrating lymphocytes. Proportional scores were defined as 3,2,1, and 0 when the area of stroma with lymphoplasmacytic infiltration around invasive tumor cell nests was $>50 \%(A) ;>10-50 \%(B) ; \leq 10 \%(C)$; and absent $(D)$, respectively.

Compared to the low-TIL group, TNBC $(p<0.001)$ and HER2BC $(p<0.001)$ were significantly more frequently found, HRBC $(p<0.001)$ was significantly less frequently identified, and $\operatorname{Ki67}(p=0.005)$ and the $\mathrm{pCR}$ rate $(p=0.003)$ were observed to be significantly higher in the high-TIL group. No correlation was observed with other clinicopathological factors (Table I) (Figure 2). DFS ( $p=0.018, \log$-rank) and OS $(p=0.027, \log$ rank) were significantly longer in the high-TIL group than in the low-TIL group (Figure 3A and B). On univariable analysis for recurrence, the high-TIL group showed more favorable prognosis than the low-TIL group $(p=0.022, \mathrm{HR}=0.42)$. Multivariable analysis also demonstrated that high-TIL status was an independent factor indicating significantly more favorable prognosis of the patients compared with those with a low-TIL status $(p=0.036, \mathrm{HR}=0.45)$ (Table II).

TILs in TNBC. Among the 61 patients with TNBC, 48 (78.7\%) were in the high-TIL group, and $13(21.3 \%)$ were in the low-TIL group. The $\mathrm{pCR}$ rate was significantly higher $(p=0.013)$ in the high-TIL group than in the low-TIL group (Table III). Outcome analysis showed significantly longer DFS $(p=0.001)$ and OS $(p=0.001)$ in the high-TIL group than that in the low-TIL group (Figure $3 \mathrm{C}$ and D). In patients with TNBC, those of the high-TIL group demonstrated significantly lower likelihood of recurrence by univariable $(p=0.004, \mathrm{HR}=0.18)$ and multivariable analysis $(p=0.023$, $\mathrm{HR}=0.24)$ (Table II).

TILs in HER2BC. Among the 36 patients with HER2BC, 25 (69.4\%) were in the high-TIL group, and $11(30.6 \%)$ were in the low-TIL group. The rates of elevated Ki67 index $(p=0.047)$ and $\mathrm{pCR}(p=0.014)$ were significantly higher in the high-TIL group than in the low-TIL group (Table III). Outcome analysis showed a significantly longer DFS $(p=0.007)$ in the high-TIL group than in the low-TIL group, but OS $(p=0.055)$ was not significantly different (Figure $3 \mathrm{E}$ and $\mathrm{F}$ ). On univariable 
Table I. Correlation between clinicopathological features and tumorinfiltrating lymphocytes (TILs) in 177 cases of breast cancer.

\begin{tabular}{|c|c|c|c|}
\hline \multirow[t]{2}{*}{ Parameter } & \multicolumn{2}{|c|}{ TILs $(n=177)$} & \multirow[t]{2}{*}{$p$-Value } \\
\hline & High $(n=96)$ & Low $(n=81)$ & \\
\hline \multicolumn{4}{|l|}{ Age at operation } \\
\hline$\leq 56$ Years & $46(47.9 \%)$ & $41(50.6 \%)$ & \\
\hline$>56$ Years & $50(52.1 \%)$ & $40(49.4 \%)$ & 0.720 \\
\hline \multicolumn{4}{|l|}{ Menopausal } \\
\hline No & $38(39.6 \%)$ & $34(42.0 \%)$ & \\
\hline Yes & $58(60.4 \%)$ & $47(58.0 \%)$ & 0.747 \\
\hline \multicolumn{4}{|l|}{ Tumor size } \\
\hline$\leq 2 \mathrm{~cm}$ & $16(16.7 \%)$ & $8(9.9 \%)$ & \\
\hline$>2 \mathrm{~cm}$ & $80(83.3 \%)$ & $73(90.1 \%)$ & 0.189 \\
\hline \multicolumn{4}{|c|}{ Lymph node status } \\
\hline Negative & $23(24.0 \%)$ & $18(22.2 \%)$ & \\
\hline Positive & $73(76.0 \%)$ & $63(77.8 \%)$ & 0.785 \\
\hline \multicolumn{4}{|l|}{ Nuclear grade } \\
\hline 1,2 & $71(74.0 \%)$ & $66(81.5 \%)$ & \\
\hline 3 & $25(26.0 \%)$ & $15(18.5 \%)$ & 0.233 \\
\hline \multicolumn{4}{|l|}{ Ki67 } \\
\hline$\leq 1 \%$ & $31(32.3 \%)$ & $43(53.1 \%)$ & \\
\hline$>14 \%$ & $65(67.7 \%)$ & $38(46.9 \%)$ & 0.005 \\
\hline \multicolumn{4}{|l|}{ Intrinsic subtype } \\
\hline TNBC & $48(50.0 \%)$ & $13(16.0 \%)$ & \\
\hline Non-TNBC & $48(50.0 \%)$ & $68(84.0 \%)$ & $<0.001$ \\
\hline \multicolumn{4}{|l|}{ Intrinsic subtype } \\
\hline HER2BC & $25(26.0 \%)$ & $11(13.6 \%)$ & \\
\hline Non-HER2BC & $71(74.0 \%)$ & $70(86.4 \%)$ & 0.040 \\
\hline \multicolumn{4}{|l|}{ Intrinsic subtype } \\
\hline HRBC & $23(24.0 \%)$ & $57(70.4 \%)$ & \\
\hline Non-HRBC & $73(76.0 \%)$ & $24(29.6 \%)$ & $<0.001$ \\
\hline \multicolumn{4}{|c|}{ Pathological response } \\
\hline $\mathrm{pCR}$ & $46(47.9 \%)$ & $21(25.9 \%)$ & \\
\hline Non-pCR & $50(52.1 \%)$ & $60(74.1 \%)$ & 0.003 \\
\hline
\end{tabular}

TNBC, Triple-negative breast cancer; HER2BC, human epidermal growth factor receptor 2-enriched breast cancer; HRBC, hormone receptor-positive breast cancer; pCR, pathological complete response.

analysis for recurrence, high-TIL status was a good prognostic factor $(p=0.026, \mathrm{HR}=0.12)$. Multivariable analysis also showed that high-TIL status was an independent good prognostic factor $(p=0.036, \mathrm{HR}=0.13)$ (Table II).

TILs in HRBC. Among the 80 patients with HRBC, 23 $(28.7 \%)$ were in the high-TIL group, and 57 (71.3\%) were in the low-TIL group. No correlation was found between TILs and any clinicopathological factor in patients with HRBC (Table III). Nor was there any correlation with outcomes (Table II; Figure 3G and H).

Changes in TILs after recurrence. Thirty patients (16.9\%) had recurrence. These included $11(36.7 \%)$ high-TIL group patients and $19(63.3 \%)$ low-TIL group patients. Among high-TIL group patients with a recurrence, four had achieved a pCR by initial NAC. Biopsy specimens in eight patients with local recurrence who originally had high TILs showed TILs had decreased in three with TNBC and two with HER2BC (Table IV). However, no changes in TILs were seen in the three patients with HRBC patients.

\section{Discussion}

Cancer cells have various gene abnormalities that allow them to proliferate spontaneously and survive, but their surrounding microenvironment also influences cancer cells and is involved in the intrinsic characteristics of cancer (2). The tumor immune environment not only influences the effects of immunotherapy, but also the effects of other anticancer drugs and treatment outcomes $(27,28)$. Thus, the importance of inhibiting and improving the tumor immune microenvironment is now recognized. Although infiltration of immunocytes is seen in tumor tissues, the production of immunosuppressive substances and induction of inhibitory immune cells, including regulatory T-cells and myeloidderived suppressor cells, leads to immunosuppression and tumor immune escape $(29,30)$.

Many anticancer drugs have immunosuppressive effects and are not very compatible with immunotherapy. However, immunological enhancement and immunosuppression elimination are possible. The mechanism of antitumor immune enhancement by anticancer drug therapy involves: improvement of immune escape on the cancer cell side (27, $31)$; induction of immunogenic death of cancer cells $(27,32)$; and improvement of immune escape on the host side $(33,34)$. The present study included patients treated with NAC using the same regimen (FEC followed by paclitaxel with/without trastuzumab). To improve immune escape on the cancer cell side, 5-fluorouracil and paclitaxel improve the sensitivity to cytotoxic T-lymphocytes $(27,31)$. In addition, the alkylating agent cyclophosphamide and anthracycline drugs induce immunogenic death of tumor cells, or so-called highly immunogenic death $(27,32)$. Moreover, in order to improve immune escape on the host side, paclitaxel inhibition of regulatory T-cells and 5-fluorouracil inhibition of myeloidderived suppressor cells have been reported $(33,34)$. In other words, this regimen as a standard for NAC in BC plays a role in enhancing the immune response based on these mechanisms.

TILs are a marker for the immune response to the tumor, and TILs are a prognostic factor in some cancer types, including predicting treatment response (3-6). The BIG0298, FinHER, ECOG2197, and ECOG1199 phase III trials in $\mathrm{BC}$ have shown that TILs are predictive of the response to NAC in TNBC and HER2-positive BC (3-6). In the BIG0298 trial of anthracycline-only chemotherapy in more than 2000 BC specimens, Loi et al. confirmed the prognostic predictive value of TILs in TNBC (5). In addition, the FinHER trial in 207 patients with HER2-positive BC showed 

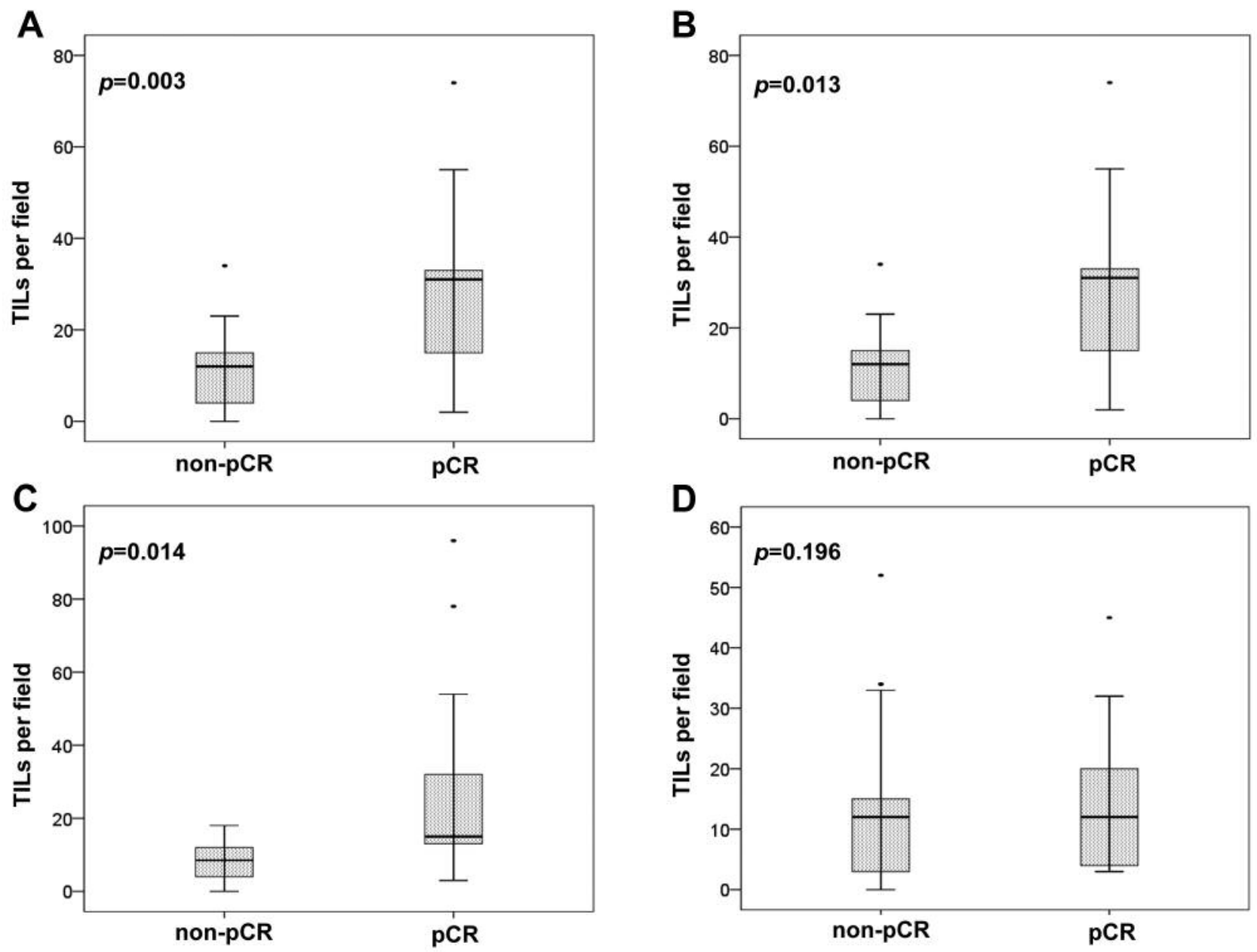

Figure 2. Tumor-infiltrating lymphocytes (TILs) and pathological complete response ( $p C R$ ) for each breast cancer subtype. Considering the whole cohort of 177 patients, the $p C R$ rate in the high-TIL group, was observed to be significantly higher compared to the low-TIL group (A), as it was in those with triple-negative breast cancer $(T N B C)(n=61)(B)$, and human epidermal growth factor receptor 2-enriched breast cancer $(H E R 2 B C)(n=36)(C)$. Among the 80 patients with hormone receptor-positive breast cancer (HRBC), no significant correlation was found between TILs and pCR rate (D).

that each $10 \%$ increase in TILs was associated with a $16 \%$ increase in the pCR rate, and that high TIL values were correlated with trastuzumab effectiveness (6). Using data from two ECOG phase III trials, Adams et al. also confirmed that lymphocyte infiltration in the stroma of TNBC was a prognostic factor in TNBC (3). These results demonstrated that TILs were able to predict treatment response only in TNBC and HER2-positive BC.

The present study also showed TILs as a useful marker to predict treatment response in TNBC and the HER2BC. However, TILs did not predict treatment response in HRBC subtypes. BC has not conventionally been regarded as a cancer that develops due to abnormal immune function (9). Recent studies, however, have shown $\mathrm{BC}$ to be an immunogenic tumor (35), and TNBC and HER2BC are now considered subtypes with high immunoreactivity $(6,7)$. An association between immune-related gene expression and TILs was shown in these subtypes, and among patients receiving NAC, those with high expression of PD-1 and cytotoxic T-lymphocyteassociated protein 4 (CTLA-4) demonstrated high pCR rates (4). In other words, in TNBC and HER2BC, genes involved with antitumor immunity were correlated with TILs.

With the accumulation of new evidence regarding TILs, attention has focused on the non-uniform methods used to date for pathological evaluation (13-15, 25). Universal criteria have been advocated for evaluation of inflammatory cell infiltration around tumors. An International Working Group (2014) announced recommendations for pathological evaluation of TILs (16). According to previous reports, some studies evaluated TILs within the tumor, but many 


\section{Disease-free survival}

\section{Overall-survival}

\section{All breast cancers $(n=177)$}

A

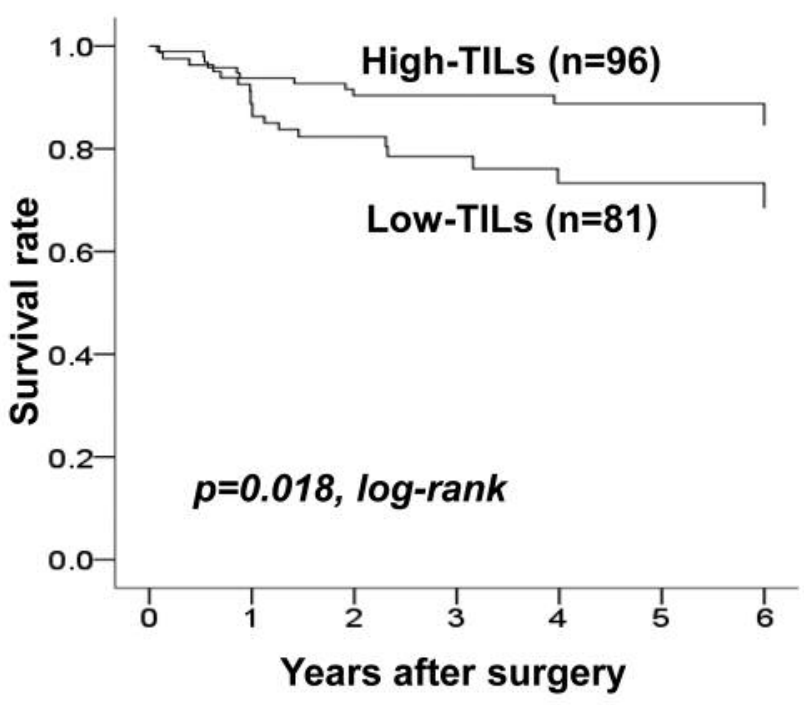

B

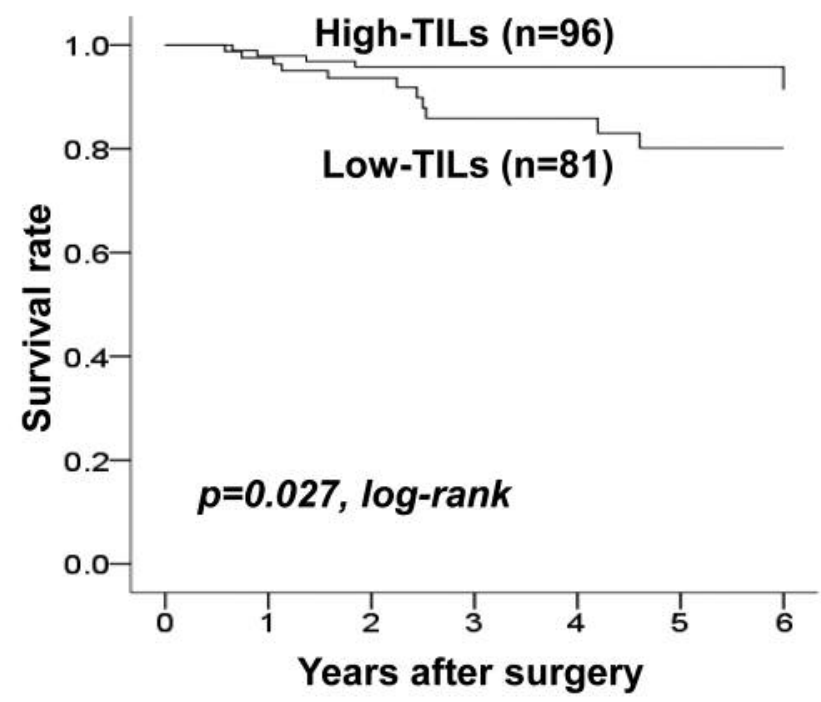

Triple-negative breast cancers $(n=61)$

C

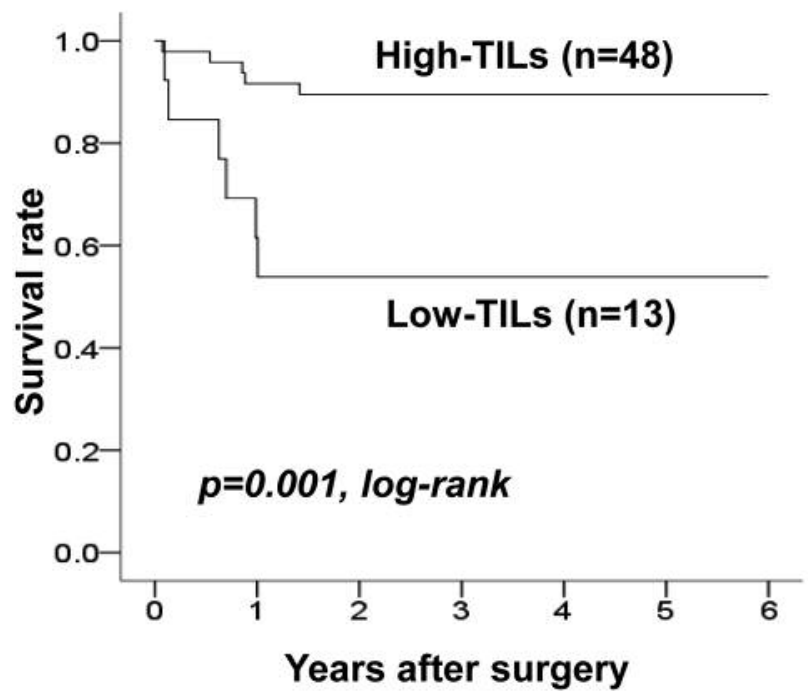

also evaluated TILs in the stroma surrounding the tumor. The current recommendations do not mention the type or ratio of lymphocytic infiltration, and the average number of TILs in the entire tumor based on hematoxylin and eosin
D

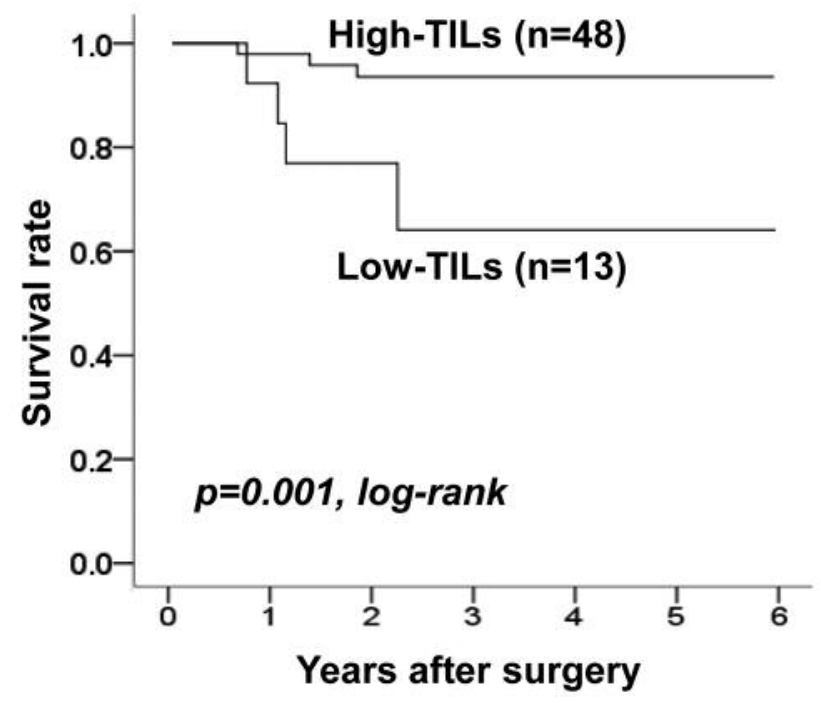

Figure 3. Continued

staining is recommended. The present study evaluated TILs according to these recommendations, and our observation were in line with the cumulative observations of the previous reports. 


\section{HER2-enriched breast cancers $(n=36)$}

$\mathbf{E}$

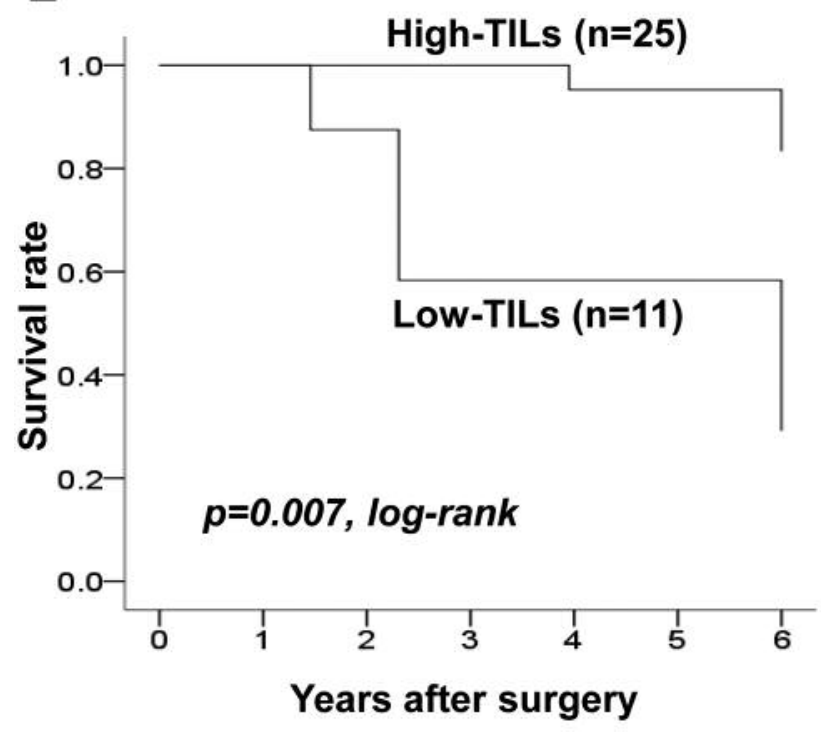

$\mathbf{F}$

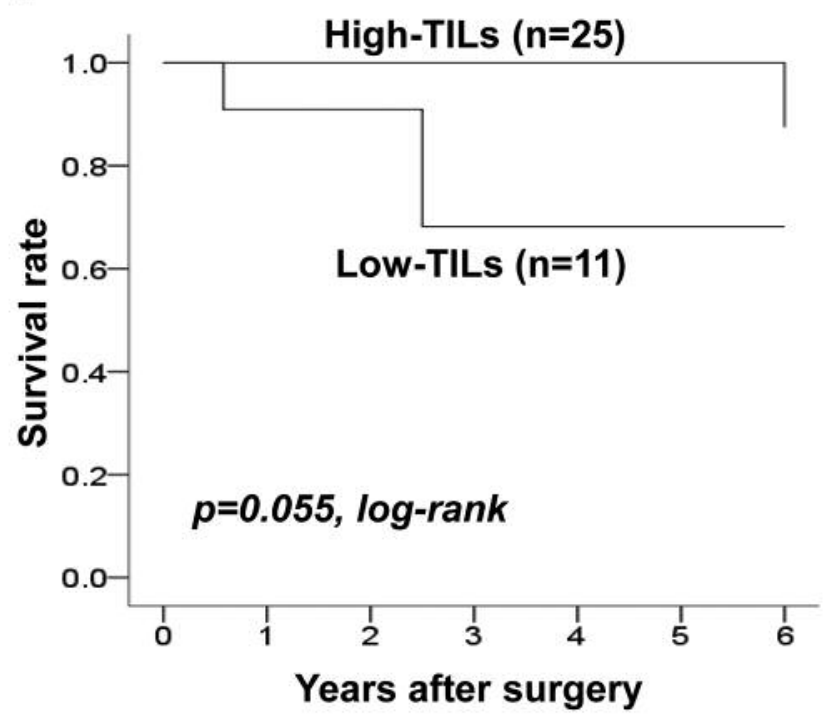

Hormone receptor-positive breast cancer $(n=80)$

G

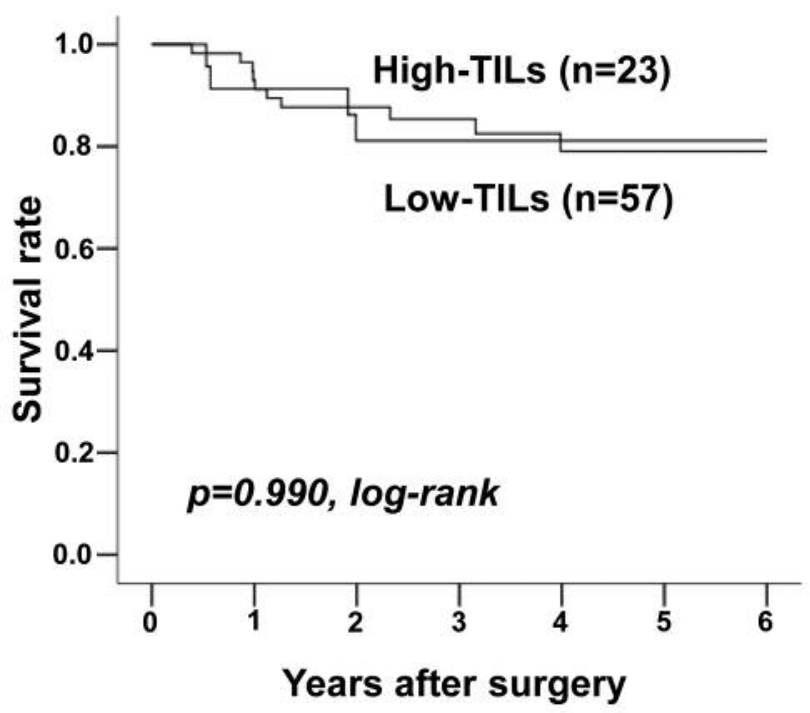

H

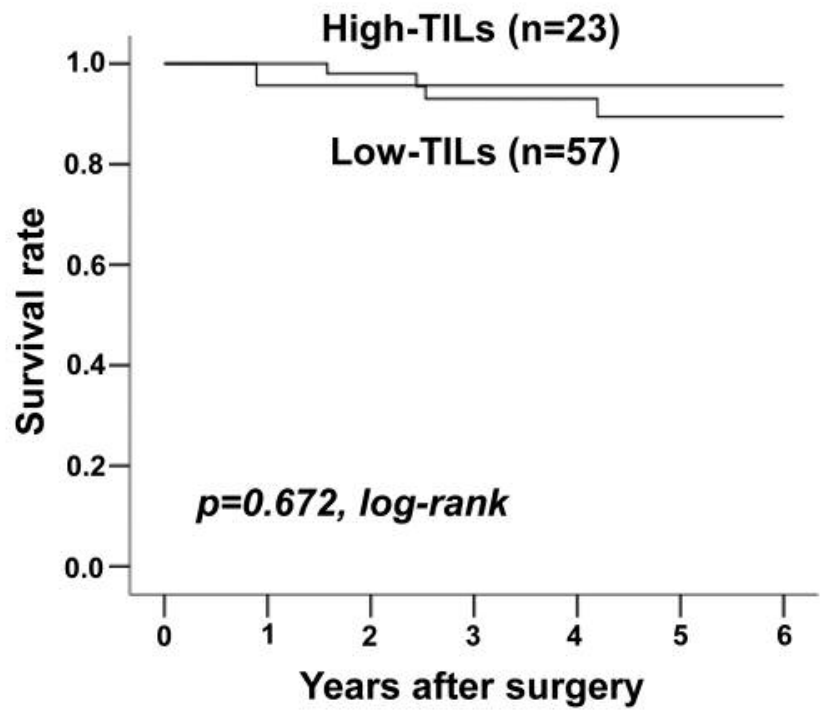

Figure 3. Prognostic analysis with tumor-infiltrating lymphocytes (TILs). Analysis of correlation with outcome of patients treated with neoadjuvant chemotherapy (NAC) showed that disease-free (DFS) and overall (OS) survival in the cohort overall (A and B), and in those with triple-negative breast cancer $(T N B C)(C)$ and $(D)$ were significantly longer in the high-TIL group than in the low-TIL group. DFS in human epidermal growth factor receptor 2-enriched breast cancer (HER2BC) was significantly longer in the high-TIL group than in the low-TIL group (D), but OS was not significantly different $(E)$. No significant difference in DFS $(F)$ or OS $(G)$ was associated with TILs in those with hormone receptor-positive breast cancer (HRBC). 
Table II. Univariable and multivariable analysis with respect to disease-free survival by breast cancer subtype.

\begin{tabular}{|c|c|c|c|c|c|c|c|}
\hline \multirow[b]{2}{*}{ Parameter } & & \multicolumn{3}{|c|}{ Univariable analysis } & \multicolumn{3}{|c|}{ Multivariable analysis } \\
\hline & & Hazard ratio & $95 \% \mathrm{CI}$ & $p$-Value & Hazard ratio & $95 \% \mathrm{CI}$ & $p$-Value \\
\hline \multicolumn{8}{|l|}{ All breast cancer $(n=177)$} \\
\hline Tumor size $(\mathrm{cm})$ & $\leq 2 v s .>2$ & 1.06 & $0.37-3.05$ & 0.911 & & & \\
\hline Lymph node status & Negative $v s$. positive & 4.16 & $0.99-17.46$ & 0.052 & & & \\
\hline Nuclear grade & $1-2$ vs. 3 & 1.03 & $0.44-2.39$ & 0.954 & & & \\
\hline Ki67 (\%) & $\leq 14$ vs. $>14$ & 0.65 & $0.32-1.33$ & 0.238 & & & \\
\hline Pathological response & pCR vs. non-pCR & 0.61 & $0.28-1.34$ & 0.217 & 0.71 & $0.32-1.56$ & 0.391 \\
\hline TILs & High $v s$. low & 0.42 & $0.20-0.89$ & 0.022 & 0.45 & $0.21-0.95$ & 0.036 \\
\hline \multicolumn{8}{|l|}{ TNBC $(n=61)$} \\
\hline Tumor size $(\mathrm{cm})$ & $\leq 2 v s .>2$ & 0.55 & $0.12-2.55$ & 0.444 & & & \\
\hline Lymph node status & Negative $v s$. positive & 0.94 & $0.20-4.36$ & 0.939 & & & \\
\hline Nuclear grade & $1-2 v s .3$ & 1.55 & $0.46-5.31$ & 0.482 & & & \\
\hline Ki67 (\%) & $\leq 14$ vs. $>14$ & 0.74 & $0.22-2.53$ & 0.630 & & & \\
\hline Pathological response & pCR $v s$. non-pCR & 0.23 & $0.05-1.08$ & 0.063 & 0.35 & $0.07-1.73$ & 0.198 \\
\hline TILs & High vs. low & 0.18 & $0.05-0.58$ & 0.004 & 0.24 & $0.07-0.82$ & 0.023 \\
\hline \multicolumn{8}{|l|}{ HER2BC $(n=36)$} \\
\hline Tumor size $(\mathrm{cm})$ & $\leq 2 v s .>2$ & 0.69 & $0.08-6.30$ & 0.744 & & & \\
\hline Lymph node status & Negative $v s$. positive & 3.73 & $0.07-5.05$ & 0.414 & & & \\
\hline Nuclear grade & $1-2$ vs. 3 & 0.04 & $0.01-5.22$ & 0.513 & & & \\
\hline $\operatorname{Ki67}(\%)$ & $\leq 14 v s .>14$ & 0.44 & $0.07-2.62$ & 0.364 & & & \\
\hline Pathological response & pCR vs. non-pCR & 0.48 & $0.08-2.85$ & 0.415 & 0.70 & $0.11-4.55$ & 0.710 \\
\hline TILs & High $v s$. low & 0.12 & $0.20-0.77$ & 0.026 & 0.13 & $0.02-0.88$ & 0.036 \\
\hline \multicolumn{8}{|l|}{$\operatorname{HRBC}(n=80)$} \\
\hline Tumor size $(\mathrm{cm})$ & $\leq 2 v s .>2$ & 2.46 & $0.32-18.84$ & 0.386 & & & \\
\hline Lymph node status & Negative $v s$. positive & 3.68 & $0.15-10.38$ & 0.205 & & & \\
\hline Nuclear grade & $1-2$ vs. 3 & 1.06 & $0.30-3.81$ & 0.930 & & & \\
\hline $\operatorname{Ki} 67(\%)$ & $\leq 14$ vs. $>14$ & 0.60 & $0.21-1.74$ & 0.344 & & & \\
\hline Pathological response & pCR $v s$. non-pCR & 1.33 & $0.44-3.97$ & 0.614 & 1.33 & $0.44-4.05$ & 0.612 \\
\hline TILs & High $v s$. low & 0.99 & $0.31-3.17$ & 0.990 & 1.04 & $0.32-3.37$ & 0.949 \\
\hline
\end{tabular}

CI, Confidence interval; TILs, tumor-infiltrating lymphocytes; TNBC, triple-negative breast cancer; HER2BC, human epidermal growth factor receptor 2-enriched breast cancer; HRBC, hormone receptor-positive breast cancer; pCR, pathological complete response.

The present study also evaluated TILs in biopsy specimens after local recurrence and investigated the association between TILs and recurrence. In patients with TNBC and HER2BC who had a recurrence, the number of TILs decreased, although there were no changes in tumor subtypes. These findings suggest that a decrease in TILs might be involved in recurrence in TNBC and HER2BC after effective treatment with NAC. Decreased tumor cell immunity in the tumor microenvironment may play a role in recurrence in these cases. Further studies utilizing immune markers are necessary to investigate the involvement of recurrence and change in the tumor microenvironment. However, as the number of recurrences were low in the present cohort, this finding should be investigated in larger studies.

In conclusion, TILs may be a biomarker predicting treatment response to NAC in patients with TNBC and HER2BC, but not with HR-positive subtypes of BC. A decrease in TILs may also be associated with tumor recurrence.

\section{Conflicts of Interest}

Authors have no conflicts of interest to disclose.

\section{Sources of Support}

This study was funded by grants from the Japan Society for the Promotion of Science (KAKENHI, Nos. 25461992, 26461957, and 17K10559) to Shinichiro Kashiwagi.

\section{Acknowledgements}

The Authors thank Yayoi Matsukiyo and Tomomi Okawa (Department of Surgical Oncology, Osaka City University Graduate School of Medicine) for helpful advice regarding data management.

\section{References}

1 Couzin-Frankel J: Breakthrough of the year 2013. Cancer immunotherapy. Science 342: 1432-1433, 2013. 
Table III. Associations between tumor-infiltrating lymphocytes (TILs) and clinicopathological parameters in 61 triple-negative (TNBC), 36 human epidermal growth factor receptor 2-enriched (HER2BC), and 80 hormone receptor-positive (HRBC) breast cancer cases.

\begin{tabular}{|c|c|c|c|c|c|c|c|c|c|}
\hline \multirow[t]{2}{*}{ Parameter } & \multicolumn{2}{|c|}{ TNBC $(n=61)$} & \multirow[b]{2}{*}{$p$-Value } & \multicolumn{2}{|c|}{ HER2BC $(n=36)$} & \multirow[b]{2}{*}{$p$-Value } & \multicolumn{2}{|c|}{$\operatorname{HRBC}(\mathrm{n}=80)$} & \multirow[b]{2}{*}{$p$-Value } \\
\hline & High $(n=48)$ & Low $(n=13)$ & & High $(n=25)$ & Low $(n=11)$ & & High $(n=23)$ & Low $(n=57)$ & \\
\hline \multicolumn{10}{|c|}{ Age at operation } \\
\hline$\leq 56$ Years & $23(47.9 \%)$ & $5(38.5 \%)$ & & $11(44.0 \%)$ & $6(54.5 \%)$ & & $12(52.2 \%)$ & $31(54.4 \%)$ & \\
\hline$>56$ Years & $25(52.1 \%)$ & $8(61.5 \%)$ & 0.544 & $14(56.0 \%)$ & $5(45.5 \%)$ & 0.936 & $11(47.8 \%)$ & $26(45.6 \%)$ & 0.857 \\
\hline \multicolumn{10}{|l|}{ Menopausal } \\
\hline No & $17(35.4 \%)$ & $5(38.5 \%)$ & & $10(40.0 \%)$ & $4(36.4 \%)$ & & $11(47.8 \%)$ & $25(43.9 \%)$ & \\
\hline Yes & $31(64.6 \%)$ & $8(61.5 \%)$ & 0.839 & $15(60.0 \%)$ & $7(63.6 \%)$ & 0.569 & $12(52.2 \%)$ & $32(56.1 \%)$ & 0.747 \\
\hline \multicolumn{10}{|l|}{ Tumor size } \\
\hline$\leq 2 \mathrm{~cm}$ & $7(14.6 \%)$ & $0(0.0 \%)$ & & $5(20.0 \%)$ & $1(9.1 \%)$ & & $4(17.4 \%)$ & $7(12.3 \%)$ & \\
\hline$>2 \mathrm{~cm}$ & $41(85.4 \%)$ & $13(100.0 \%)$ & 0.169 & $20(80.0 \%)$ & $10(90.9 \%)$ & 0.391 & $19(82.6 \%)$ & $50(87.7 \%)$ & 0.391 \\
\hline \multicolumn{10}{|c|}{ Lymph node status } \\
\hline Negative & $8(16.7 \%)$ & $3(23.1 \%)$ & & $8(32.0 \%)$ & $3(27.3 \%)$ & & $7(30.4 \%)$ & $12(21.1 \%)$ & \\
\hline Positive & $40(83.3 \%)$ & $10(76.9 \%)$ & 0.430 & $17(68.0 \%)$ & $8(72.7 \%)$ & 0.551 & $16(69.6 \%)$ & $45(78.9 \%)$ & 0.372 \\
\hline \multicolumn{10}{|c|}{ Nuclear grade } \\
\hline 1,2 & $36(75.0 \%)$ & $8(61.5 \%)$ & & $18(72.0 \%)$ & $10(90.9 \%)$ & & $17(73.9 \%)$ & $48(84.2 \%)$ & \\
\hline 3 & $12(25.0 \%)$ & $5(38.5 \%)$ & 0.265 & $7(28.0 \%)$ & $1(9.1 \%)$ & 0.210 & $6(26.1 \%)$ & $9(15.8 \%)$ & 0.286 \\
\hline \multicolumn{10}{|l|}{ Ki67 } \\
\hline$\leq 14 \%$ & $14(29.2 \%)$ & $4(30.8 \%)$ & & $9(36.0 \%)$ & $8(72.7 \%)$ & & $8(34.8 \%)$ & $31(54.4 \%)$ & \\
\hline$>14 \%$ & $34(70.8 \%)$ & $9(69.2 \%)$ & 0.580 & $16(74.0 \%)$ & $3(27.3 \%)$ & 0.047 & $15(65.2 \%)$ & $26(45.6 \%)$ & 0.112 \\
\hline \multicolumn{10}{|c|}{ Pathological response } \\
\hline $\mathrm{pCR}$ & $26(54.2 \%)$ & $2(15.4 \%)$ & & $9(36.0 \%)$ & $9(81.8 \%)$ & & $4(17.4 \%)$ & $17(29.8 \%)$ & \\
\hline Non-pCR & $22(45.8 \%)$ & $11(84.6 \%)$ & 0.013 & $16(74.0 \%)$ & $2(18.2 \%)$ & 0.014 & $19(82.6 \%)$ & $40(70.2 \%)$ & 0.196 \\
\hline
\end{tabular}

pCR, Pathological complete response.

Table IV. Changes in tumor-infiltrating lymphocytes (TILs) after recurrence.

\begin{tabular}{|c|c|c|c|c|c|c|c|c|c|c|}
\hline No. & $\begin{array}{l}\text { Age, } \\
\text { years }\end{array}$ & Menopausal & $\begin{array}{l}\text { Tumor } \\
\text { size } \\
(\mathrm{cm})\end{array}$ & $\begin{array}{l}\text { Lymph } \\
\text { node } \\
\text { status }\end{array}$ & $\begin{array}{l}\text { Intrinsic } \\
\text { subtype }\end{array}$ & $\begin{array}{l}\text { Pathological } \\
\text { response }\end{array}$ & $\begin{array}{l}\text { Disease-free } \\
\text { interval } \\
\text { (years) }\end{array}$ & $\begin{array}{l}\text { TILs of CNB } \\
\text { specimens } \\
\text { before NAC }\end{array}$ & $\begin{array}{l}\text { TILs of surgical } \\
\text { specimens } \\
\text { after NAC }\end{array}$ & $\begin{array}{l}\text { TILs of CNB } \\
\text { specimens after } \\
\text { recurrence }\end{array}$ \\
\hline 1 & 53 & Yes & 2.8 & Positive & TNBC & Non-pCR & 0.85 & High & High & Low \\
\hline 2 & 44 & No & 2.6 & Positive & TNBC & Non-pCR & 0.54 & High & Low & Low \\
\hline 3 & 68 & Yes & 3.0 & Positive & TNBC & Non-pCR & 0.88 & High & Low & Low \\
\hline 4 & 58 & Yes & 2.8 & Positive & HER2BC & Non-pCR & 1.95 & High & High & Low \\
\hline 5 & 71 & Yes & 1.9 & Positive & HER2BC & Non-pCR & 1.76 & High & Low & Low \\
\hline 6 & 45 & No & 1.7 & Positive & HRBC & Non-pCR & 0.53 & High & High & High \\
\hline 7 & 47 & No & 2.3 & Positive & HRBC & Non-pCR & 0.57 & High & High & High \\
\hline 8 & 55 & Yes & 2.2 & Positive & HRBC & pCR & 1.92 & High & NA & High \\
\hline 9 & 75 & Yes & 2.9 & Positive & HRBC & $\mathrm{pCR}$ & 1.99 & High & NA & NA \\
\hline 10 & 46 & No & 2.5 & Positive & TNBC & $\mathrm{pCR}$ & 1.41 & High & NA & NA \\
\hline 11 & 40 & No & 3.8 & Negative & TNBC & pCR & 0.08 & High & NA & NA \\
\hline
\end{tabular}

TNBC, Triple-negative breast cancer. HER2BC, human epidermal growth factor receptor 2-enriched breast cancer. HRBC, hormone receptor-positive breast cancer. pCR, pathological complete response. CNB, core-needle biopsy. NAC, neoadjuvant chemotherapy. NA, not available.

2 Hanahan D and Weinberg RA: Hallmarks of cancer: the next generation. Cell 144: 646-674, 2011.

3 Adams S, Gray RJ, Demaria S, Goldstein L, Perez EA, Shulman LN, Martino S, Wang M, Jones VE, Saphner TJ, Wolff AC, Wood WC, Davidson NE, Sledge GW, Sparano JA and Badve SS: Prognostic value of tumor-infiltrating lymphocytes in triplenegative breast cancers from two phase III randomized adjuvant breast cancer trials: ECOG 2197 and ECOG 1199. J Clin Oncol 32: 2959-2966, 2014.

4 Denkert C, von Minckwitz G, Brase JC, Sinn BV, Gade S, Kronenwett R, Pfitzner BM, Salat C, Loi S, Schmitt WD, Schem C, Fisch K, Darb-Esfahani S, Mehta K, Sotiriou C, Wienert S, Klare P andre F, Klauschen F, Blohmer JU, Krappmann K, Schmidt M, Tesch H, Kummel S, Sinn P, Jackisch C, Dietel M, 
Reimer T, Untch M and Loibl S: Tumor-infiltrating lymphocytes and response to neoadjuvant chemotherapy with or without carboplatin in human epidermal growth factor receptor 2positive and triple-negative primary breast cancers. J Clin Oncol 33: 983-991, 2015.

5 Loi S, Sirtaine N, Piette F, Salgado R, Viale G, Van Eenoo F, Rouas G, Francis P, Crown JP, Hitre E, de Azambuja E, Quinaux E, Di Leo A, Michiels S, Piccart MJ and Sotiriou C: Prognostic and predictive value of tumor-infiltrating lymphocytes in a phase III randomized adjuvant breast cancer trial in node-positive breast cancer comparing the addition of docetaxel to doxorubicin with doxorubicin-based chemotherapy: BIG 02-98. J Clin Oncol 31: 860-867, 2013.

6 Loi S, Michiels S, Salgado R, Sirtaine N, Jose V, Fumagalli D, Kellokumpu-Lehtinen PL, Bono P, Kataja V, Desmedt C, Piccart MJ, Loibl S, Denkert C, Smyth MJ, Joensuu H and Sotiriou C: Tumor-infiltrating lymphocytes are prognostic in triple negative breast cancer and predictive for trastuzumab benefit in early breast cancer: results from the FinHER trial. Ann Oncol 25: 1544-1550, 2014.

7 Loi S: Tumor-infiltrating lymphocytes, breast cancer subtypes and therapeutic efficacy. Oncoimmunology 2: e24720, 2013.

8 Schreiber RD, Old LJ and Smyth MJ: Cancer immunoediting: integrating immunity's roles in cancer suppression and promotion. Science 331: 1565-1570, 2011.

9 Rosenberg SA, Yang JC and Restifo NP: Cancer immunotherapy: moving beyond current vaccines. Nat Med 10: 909-915, 2004.

10 Sun S, Fei X, Mao Y, Wang X, Garfield DH, Huang O, Wang J, Yuan F, Sun L, Yu Q, Jin X, Wang J and Shen K: PD-1(+) immune cell infiltration inversely correlates with survival of operable breast cancer patients. Cancer Immunol Immunother 63: 395-406, 2014.

11 Muenst S, Schaerli AR, Gao F, Daster S, Trella E, Droeser RA, Muraro MG, Zajac P, Zanetti R, Gillanders WE, Weber WP and Soysal SD: Expression of programmed death ligand 1 (PD-L1) is associated with poor prognosis in human breast cancer. Breast Cancer Res Treat 146: 15-24, 2014.

12 Stagg J and Allard B: Immunotherapeutic approaches in triplenegative breast cancer: latest research and clinical prospects. Ther Adv Med Oncol 5: 169-181, 2013.

13 Denkert C, Loibl S, Noske A, Roller M, Muller BM, Komor M, Budczies J, Darb-Esfahani S, Kronenwett R, Hanusch C, von Torne C, Weichert W, Engels K, Solbach C, Schrader I, Dietel $\mathrm{M}$ and von Minckwitz G: Tumor-associated lymphocytes as an independent predictor of response to neoadjuvant chemotherapy in breast cancer. J Clin Oncol 28: 105-113, 2010.

14 West NR, Milne K, Truong PT, Macpherson N, Nelson BH and Watson PH: Tumor-infiltrating lymphocytes predict response to anthracycline-based chemotherapy in estrogen receptor-negative breast cancer. Breast Cancer Res 13: R126, 2011.

15 Ono M, Tsuda H, Shimizu C, Yamamoto S, Shibata T, Yamamoto $\mathrm{H}$, Hirata $\mathrm{T}$, Yonemori $\mathrm{K}$ ando $\mathrm{M}$, Tamura $\mathrm{K}$, Katsumata N, Kinoshita T, Takiguchi Y, Tanzawa H and Fujiwara Y: Tumor-infiltrating lymphocytes are correlated with response to neoadjuvant chemotherapy in triple-negative breast cancer. Breast Cancer Res Treat 132: 793-805, 2012.

16 Salgado R, Denkert C, Demaria S, Sirtaine N, Klauschen F, Pruneri G, Wienert S, Van den Eynden G, Baehner FL, PenaultLlorca F, Perez EA, Thompson EA, Symmans WF, Richardson AL, Brock J, Criscitiello C, Bailey H, Ignatiadis M, Floris G,
Sparano J, Kos Z, Nielsen T, Rimm DL, Allison KH, Reis-Filho JS, Loibl S, Sotiriou C, Viale G, Badve S, Adams S, WillardGallo K, Loi S and International TWG: The evaluation of tumorinfiltrating lymphocytes (TILs) in breast cancer: recommendations by an International TILs Working Group 2014. Ann Oncol 26: 259-271, 2015.

17 Dieci MV, Criscitiello C, Goubar A, Viale G, Conte P, Guarneri V, Ficarra G, Mathieu MC, Delaloge S, Curigliano G and Andre F: Prognostic value of tumor-infiltrating lymphocytes on residual disease after primary chemotherapy for triple-negative breast cancer: a retrospective multicenter study. Ann Oncol 25: 611618, 2014.

18 Greene FL and Sobin LH: A worldwide approach to the TNM staging system: collaborative efforts of the AJCC and UICC. J Surg Oncol 99: 269-272, 2009.

19 Wolff AC, Hammond ME, Hicks DG, Dowsett M, McShane LM, Allison KH, Allred DC, Bartlett JM, Bilous M, Fitzgibbons P, Hanna W, Jenkins RB, Mangu PB, Paik S, Perez EA, Press MF, Spears PA, Vance GH, Viale G, Hayes DF, American Society of Clinical Oncology and College of American Pathologists: Recommendations for human epidermal growth factor receptor 2 testing in breast cancer: American Society of Clinical Oncology/College of American Pathologists clinical practice guideline update. J Clin Oncol 31: 3997-4013, 2013.

20 Mauri D, Pavlidis N and Ioannidis JP: Neoadjuvant versus adjuvant systemic treatment in breast cancer: a meta-analysis. J Natl Cancer Inst 97: 188-194, 2005.

21 Mieog JS, van der Hage JA and van de Velde CJ: Preoperative chemotherapy for women with operable breast cancer. Cochrane Database Syst Rev 2: CD005002, 2007.

22 Buzdar AU, Valero V, Ibrahim NK, Francis D, Broglio KR, Theriault RL, Pusztai L, Green MC, Singletary SE, Hunt KK, Sahin AA, Esteva F, Symmans WF, Ewer MS, Buchholz TA and Hortobagyi GN: Neoadjuvant therapy with paclitaxel followed by 5-fluorouracil, epirubicin and cyclophosphamide chemotherapy and concurrent trastuzumab in human epidermal growth factor receptor 2-positive operable breast cancer: an update of the initial randomized study population and data of additional patients treated with the same regimen. Clin Cancer Res 13: 228-233, 2007.

23 Eisenhauer EA, Therasse P, Bogaerts J, Schwartz LH, Sargent D, Ford R, Dancey J, Arbuck S, Gwyther S, Mooney M, Rubinstein L, Shankar L, Dodd L, Kaplan R, Lacombe D and Verweij J: New response evaluation criteria in solid tumours: revised RECIST guideline (version 1.1). Eur J Cancer 45: 228247, 2009.

24 Wolmark N, Wang J, Mamounas E, Bryant J and Fisher B: Preoperative chemotherapy in patients with operable breast cancer: nine-year results from National Surgical Adjuvant Breast and Bowel Project B-18. J Natl Cancer Inst Monogr: 96-102, 2001.

25 Mao Y, Qu Q, Zhang Y, Liu J, Chen X and Shen K: The value of tumor infiltrating lymphocytes (TILs) for predicting response to neoadjuvant chemotherapy in breast cancer: a systematic review and meta-analysis. PLoS One 9: e115103, 2014.

26 Kashiwagi S, Asano Y, Goto W, Takada K, Takahashi K, Hatano T, Takashima T, Tomita S, Motomura H, Ohsawa M, Hirakawa $\mathrm{K}$ and Ohira M: Using TILs to predict therapeutic effect of chemotherapy (pertuzumab, trastuzumab, docetaxel) on HER2positive breast cancer. Anticancer Res 37: 5623-5630, 2017. 
27 Zitvogel L, Kepp O and Kroemer G: Immune parameters affecting the efficacy of chemotherapeutic regimens. Nat Rev Clin Oncol 8: 151-160, 2011.

28 Dougan $M$ and Dranoff G: Immune therapy for cancer. Annu Rev Immunol 27: 83-117, 2009.

29 Jacobs JF, Nierkens S, Figdor CG, de Vries IJ and Adema GJ: Regulatory $\mathrm{T}$ cells in melanoma: The final hurdle towards effective immunotherapy? Lancet Oncol 13: e32-42, 2012.

30 Nishikawa H and Sakaguchi S: Regulatory T-cells in tumor immunity. Int J Cancer 127: 759-767, 2010.

31 Vacchelli E, Galluzzi L, Fridman WH, Galon J, Sautes-Fridman C, Tartour E and Kroemer G: Trial watch: Chemotherapy with immunogenic cell death inducers. Oncoimmunology 1: 179-188, 2012.

32 Yaguchi T, Sumimoto H, Kudo-Saito C, Tsukamoto N, Ueda R, Iwata-Kajihara T, Nishio H, Kawamura N and Kawakami Y: The mechanisms of cancer immunoescape and development of overcoming strategies. Int J Hematol 93: 294-300, 2011.
33 Galluzzi L, Senovilla L, Zitvogel L and Kroemer G: The secret ally: immunostimulation by anticancer drugs. Nat Rev Drug Discov 11: 215-233, 2012.

34 Ramakrishnan R and Gabrilovich DI: Mechanism of synergistic effect of chemotherapy and immunotherapy of cancer. Cancer Immunol Immunother 60: 419-423, 2011.

35 Zhou J and Zhong Y: Breast cancer immunotherapy. Cell Mol Immunol 1: 247-255, 2004.
Received December 5, 2017

Revised January 5, 2018

Accepted February 5, 2018 